\title{
Newspaper Reading Comprehension Development through Vocabulary or Structure Instruction
}

Samane Naderi

Ph.D. Student

TEFL, English Department

Yazd University, Yazd, Iran

samane.naderi61@gmail.com

Ali Fazilatfar

Associate Professor, Ph.D.

Applied Linguistics \& TESL

English Department

Yazd University

Yazd, Iran

afazilatfar@yahoo.com

Abstract

The purpose of this study is investigating the effect of specific vocabularies and structures instruction on the upper intermediate EFL learners' newspaper reading comprehension development. For this purpose, fifty four female upper intermediate EFL learners were 
selected and randomly assigned in three groups each consisting of eighteen learners, two experimental and one control. At the first session,a researcher-made newspaper reading comprehension test was applied as the pretest. The learners of one experimental group received instruction of newspaper structures and the other one received related vocabularies instruction and the control one received just translation of newspaper content by the teacher. In the last session, another researcher-made comprehension test was administered for three groups as the post test. The findings indicate thatstructure instruction is significantly the most beneficial one and the mere translation of newspaper content is the least beneficial in developing learner's newspaper reading comprehension. The results of interviews confirmed the study findings as well.

Keywords: Newspaper Reading Comprehension; Authentic Materials; Vocabulary Instruction; Structure Instruction

\section{Introduction}

Recently, using authentic materials including newspaper in educational settings attracts teachers' and learners' attention. The specific feature of newspaper is its every day development and its freshness. It contains the latest information with many attractive details. The newspaper can be considered as an optimal living material for education purposes specifically in language learning and teaching process. It can be applied to improve skills such writing, reading, speaking, listening, and even social studies. Comparing textbooks and authentic materials, authentic materials are more interactive and demonstrate real life language unlike the textbooks that are mostly instrumental for education goals. To achieve native-like proficiency, merely applying instrumentalmaterials is not sufficient in English instruction. (Zohoorian and Baghban, 2011). 
According to Lin (2004), the significance of authentic materials instruction in authentic contexts in comparison with instruction of pedagogical materials has been taken into account by communicative perspectives. Applying authentic materials refers to the advent of communicative approaches through which real world condition is stimulated in the classroom environment (Guariento and Morley, 2001). Usefulness of authenticity in language learning and teaching process was previously confirmed doubtlessly (Shrum and Glisan, 2000; Richards, 2001; Kilickaya, 2004, etc).

Among authentic materials newspaper is regarded as are liable source of information (JarmanandMcClune, 2002; Korpan et al, 1997). Newspapers include scientific knowledge which is needed for critical thinking and can affect the person's attitudes, beliefs and behaviors. (Norris et al, 2003). Therefore, comprehending and assessing the newspapers' scientific reports is considered as an obvious characteristic of a scientifically literate individual (Korpan et al, 1997;Wellington, 1991).

An extensive literature, investigating the issue of using authentic materials including newspapers for language development, demonstrates that applying such kinds of materials are very helpful in language learning development. Although, practical evidences of how applying such materials for teaching purposes can help learners in their learning process are scarce. The present study aims at investigating the effect of specific vocabularies and structures instruction on the upper intermediate EFL learners' newspaper reading comprehension development.

\section{Authentic Materials}

Based on Morrow's definition (1977), authentic materials refer to the language provided by an actual speaker or writer for a real addressee to convey a real message. Also authentic materials can be defined as the natural samples of oral and written language which 
are context-based (Rogers and Medley,1988). Nunan (1989) believes that authentic materials are not specifically produced for language instruction.

Authenticity is classified by Breen (1985) into four types: authenticity of text which is applied as the input, learners' interpretation of the texts authenticity, language learning tasks authenticity and the real social context authenticity in the classroom. Breen mentions that the first two authenticities are related to the learners and the teachers should help them in the texts interpretation. For the second two kinds of authenticity, Breen points out to the authentic learning tasks. Breen argues that an authentic task should contain a communicative essence and merely the educational settings can judge the task authenticity.

Widdowson (1998) distinguishes authenticity from genuineness in this way that a genuine text cannot be authentic necessarily because there are two characteristics for having authenticity. The first one is related to the text itself and another one is referred to the addressee of the text. According to Taylor (1994), the nature of authenticity is not placed in the material but it is referred to a specific condition with specific addressee. Unlike Widdowson he believes that a classroom environment can be authentic and can stimulate the real situations. According to him, authenticity is not an attribute only related to the text but it can be considered as the way the learners and the teachers deal with the text.

In spite of having authentic materials, authenticity may not be achieved if the learner does not answer to the text as a native speaker does in actual situation, or if an authentic task is not applied according to the text. Therefore, instead of mere concentrating on the authentic materials, the teachers should pay attention to the authentic materials' application (Anderson, 1999 and Velazquez, 2007).

Newspaper Reading Comprehension 
It should be taken into account that the written science in newspapers is really different from the written science in academic texts. The goal of scientific news in newspapers is communicating not instructing the science. A newspaper can include various kinds of texts with scientific content with the aim of conveying some scientific knowledge, describing an issue related to the science or proposing an idea (Oliveras, Marquez and Sanmarti, 2013).

As previously mentioned, the main objective of the newspaper is communication; thus, the scientific information in the newspapers includes little particular knowledge which interrupts communication. Consequently, reading comprehension of scientific texts, which are not directly provided for teaching purpose, becomes difficult for the learners. In newspapers, some scientific facts can be seen but the related evidences for them may not be seen or even may not be identifiable (Martins, Mortimer, Osborne, Tsatarelis and JimenezAleixandre, 2001; Márquezand Prat, 2005).

To have an appropriate interpretation of newspaper's scientific content, the learners should activate their previous scientific background knowledge which has been acquired at school that in some situations it is difficult for learners to make this activation and connection (Millar, 2006).

\section{Statement of the Research Questions}

In order to address the aim of the study the following research questions were posed:

1. Does the specific vocabularies and structures instruction have any significant effects on the upper intermediate EFL learners' newspaper reading comprehension development? 
2. Is there any significant difference between the effect of specific vocabularies instruction and specific structures instruction on the upper intermediate EFL learners' newspaper reading comprehension development?

3. What is the upper intermediate EFL learners' attitudes towards the effect of the specific vocabularies and structures instruction on their newspaper reading comprehension development?

Methodology

Participants

To achieve the purpose of this study, the researchers selected three groups each consists of 18 female upper intermediate EFL learners. Total number of participants were fifty four Iranian female upper intermediate EFL learners in Mashhad.Their ages ranged from 23 to 48 and they came from different socio-economic backgrounds. Their educational levels varied from BA to MA degree in the majors other than English.

\section{Instrumentation}

1. At the beginning, the Oxford Placement Test (Allan 1995) for theupper intermediate was applied to homogenize the subjects. Based on the score guidelines of the test, fifty four upper intermediate EFL learners were selected out of 65 ones. They were also evaluated through interview by some experts to ensure their level of proficiency.

2. To examine the pre-existing differences among the learners in the terms of newspaper reading comprehension and to investigate their comprehension differences after fulfilment of the treatment, two researcher-made tests were designed one of which was applied as the pretest and the other one was used as the post test. Each researcher- 
made test consisted of two newspaper's articles each followed by five multiple choice comprehension questions about the text. The tests were validated by two related experts; also they were piloted among 18 upper intermediate EFL learners and their Cronbach's alpha were calculated (pretest: 0.741 and posttest: 0.785 ).

\section{Study Design}

The quasi-experimental design was applied for this study because it is an empirical interventional study without any randomization in sampling.

\section{Procedure}

At first, to ensure that the participants were at the approximately same level of English proficiency, the Oxford Placement Test (Allan 1995) for the upper intermediate was applied for the subjects. Based on the score guidelines of the test, fifty four upper intermediate EFL learners were selected out of 65 ones. They were also evaluated through interview by some experts to ensure their level of proficiency. The selected learners were assigned randomly to three groups, two experimental groups and one control group. At the first session, one of the researcher-made tests was administered as the pre-test for the members of three groups to investigate whether there are any differences among the all three groups' learners' newspaper reading comprehension before treatment implementation. In one experimental group, just the specific and related vocabularies were taught and practiced. The style of the instruction in this group was based on the glossary. In this style the learners apply different strategies to analyze vocabularies; for instance, they were asked to pick an article from the specific section of a newspaper. As they skim the article, they should provide a list of the related vocabularies that are used in that section. After that, they were needed to define each word and in some cases they should draw a related picture to demonstrate the meanings 
of the vocabularies. Then, they should add other related words that came into their minds or even by searching through the internet. At the end, they had glossary in specific section. All this process was done in the groups of three learners and the groups were sharing their glossaries with each other to rich their own glossaries. In another experimental group, the specific related structures of newspaper content were instructed and practiced; for example, the teacher taught the style of headline writing including some needed ellipses and the rules of headline briefness. Then the learners were provided some articles with headlines and they should analyze the headlines and recognize the specific structures that were applied in them. When they got familiar with the related structures by analyzing several different headlines in different subjects, they were provided with some articles without headline and the learners were needed to produce the related headlines using the taught structures. Again all this process was done in the groups of three learners and the groups were sharing their headlines with each other to select the best one and the teacher compared the final selected one with original headline to examine how the selected one approximate the original one. In the control group, the teacher just translated some selected articles from the newspaper and the learners were just needed to write the translation. The treatments were fulfilled during two weeks, three times in each week, totally six sessions. At the last session, another researchermade test was used for all three groups as the post test. In that session four learners of each group were interviewed and were asked their attitudes about the styles of instruction they had experienced.

\section{Data analysis}

The first phase of data analysis is the pilot study of the researcher-made tests.

Because three independents variables are included in the study, to address the first two research questions of the study, Analysis of Variance (ANOVA) test was used. It is used to 
determine whether there are any differences between independent groups on a dependent variable.

Results

To address the first two research questions of the study, data collected through the posttest and pre-test and some statistical procedures were applied to the data. For this purpose, SPSS, version 19, was used. Firstly, the descriptive statistics for pretest were applied which were displayed in table 1.

Table 1: Descriptive Statistics of the three groups at the pretest of newspaper reading comprehension

95\% Confidence

Interval for Mean

Std. Std. $\quad$ Lower Upper Minimu Maxim

\begin{tabular}{|c|c|c|c|c|c|c|c|}
\hline $\mathrm{N}$ & Mean & Deviation & Error & Bound & Bound & $\mathrm{m}$ & um \\
\hline rretest EXvoc 18 & 3.0000 & 1.53393 & 3615 & 2.2372 & 3.7628 & 1.00 & 6.00 \\
\hline
\end{tabular}

\begin{tabular}{lllllllll}
\hline EXstru & & & & & & & & \\
& 18 & 2.6111 & 1.09216 & .25742 & 2.0680 & 3.1542 & 1.00 & 5.00 \\
ct & & & & & & & & \\
& & & & & & & & \\
\hline control 18 & 2.5556 & 1.29352 & .30489 & 1.9123 & 3.1988 & 1.00 & 6.00 \\
\hline Total 54 & 2.7222 & 1.30914 & .17815 & 2.3649 & 3.0795 & 1.00 & 6.00
\end{tabular}

To evaluate whether there are any significant differences in learners' newspaper reading comprehension of three groups before treatment implementation and whether they are suitable for the study, the mean scores of the three groups at the pre-test were compared by the use of a one-way ANOVA. The F-observed value and p-value were .607 and .549 , respectively. This amount of F-value at 2 and 51 degrees of freedom was lower than the critical value of $\mathrm{F}$ and p-value was higher than the significance level of .05 (see Table 2). 
Table 2: One-Way ANOVA on the three groups at the pretest of newspaper reading comprehension

\begin{tabular}{|c|c|c|c|c|c|}
\hline & & Sum & $f$ & & \\
\hline & & Squares & df & Mean Square F & Sig. \\
\hline \multirow[t]{3}{*}{ pretest } & Between Groups & 2.111 & 2 & 1.056 & .549 \\
\hline & Within Groups & 88.722 & 51 & 1.740 & \\
\hline & Total & 90.833 & 53 & & \\
\hline
\end{tabular}

According to table 2, there was no significant difference between the mean scores of the three groups at the pre-test $(\mathrm{F}(2,51)=.607, \mathrm{p}>.05)$; therefore, these groups are suitable ones for this study.

The result of the Levene's test of homogeneity of variance illustrates that the three groups have homogenous variance; it means that, there was not any significant differences among the variances of the three groups (see Table 3).

Table 3: Test of Homogeneity of Variances at pretest

\begin{tabular}{lccc}
\hline Levene Statistic & df1 & df2 & Sig. \\
\hline .848 & 2 & 51 & .434
\end{tabular}

Based on the table 3, the results of the one-way ANOVA were reliable $(F(2,57)=.607, p>$ $.05)$

The descriptive statistics for the three groups at the post-test are displayed in Table 4. 
Table 4: Descriptive Statistics of the three Groups at the Post-Test.

$95 \% \quad$ Confidence

Interval for Mean

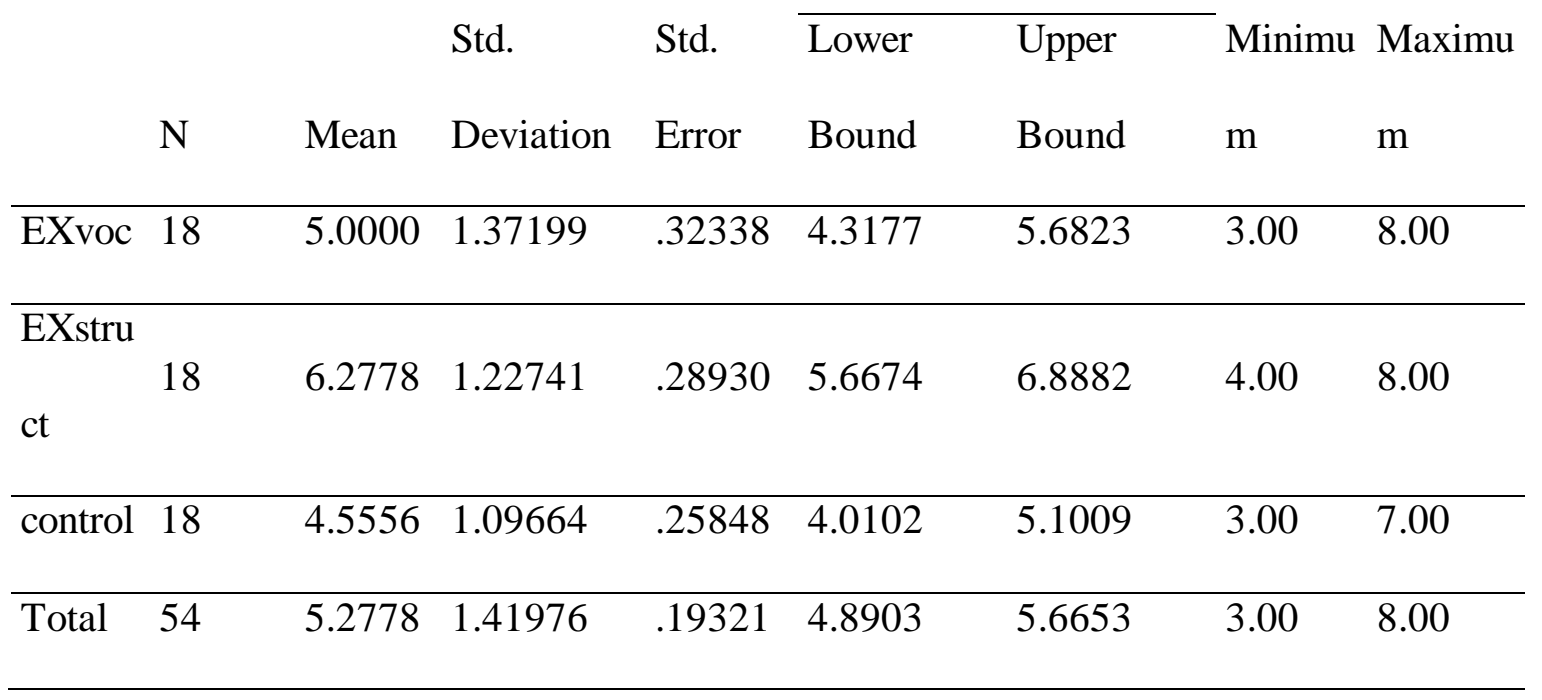

The mean of experimental group with structure instruction at the post-test is higher than the other two.

To evaluate whether the treatments led to the differences, the mean scores of the three groups at the post-test were compared by the application of a one-way ANOVA. The Fobserved value and p-value were 9.401 and .000 respectively. This amount of F-value at 2 and 41 degrees of freedom was higher than the critical value of $F$, and p-value was lower than the significance level of $.05(\mathrm{~F}(2,57)=9.401, \mathrm{p}<.05($ see Table 5$)$ :

Table 5: One-Way ANOVA on the three groups at the Post-Test.

\begin{tabular}{llclll}
\hline & Sum & of & & & \\
& Squares & df & Mean Square & F & Sig. \\
\hline Between Groups & 28.778 & 2 & 14.389 & 9.401 & .000 \\
\hline Within Groups & 78.056 & 51 & 1.531 & & \\
\hline Total & 106.833 & 53 & & & \\
\hline
\end{tabular}


According to the results of table 5, it can be concluded that there are significant differences among the mean scores of the three groups on post-test.

The Leven's test of homogeneity of variance reveals that the three groups possessed homogenous variance $(\mathrm{F}(2,57)=9.401, \mathrm{p}>.05) .($ see table 7$)$

Table 6: Test of Homogeneity of Variances at posttest

\begin{tabular}{lccc}
\hline Levene Statistic & df1 & df2 & Sig. \\
\hline .485 & 2 & 51 & .032
\end{tabular}

Thus, the results of the one-way ANOVA are reliable. It means that there were no significant differences among the variances of the three groups.

The result of one-way ANOVA shows that there are differences among the means of three groups, but their exact places were not determined. To indicate the precise place of differences, a post hoc comparison of the means was conducted. (see Table 7).

Table 7: Bonferroni test for the comparison of posttest means of the three groups

\begin{tabular}{|c|c|c|c|c|c|c|}
\hline \multirow[b]{2}{*}{ I) group } & \multirow[b]{2}{*}{ (J) group } & \multicolumn{3}{|l|}{ Mean } & \multicolumn{2}{|c|}{ 95\% Confidence Interval } \\
\hline & & Difference $(\mathrm{I}-\mathrm{J})$ & Std. Error & Sig. & Lower Bound & Upper Bound \\
\hline \multirow[t]{2}{*}{ EXvoc } & EXstruct & $-1.27778^{*}$ & .41238 & .009 & -2.2986 & -.2569 \\
\hline & control & $1.44444^{*}$ & .41238 & .029 & -1.5764 & 1.4653 \\
\hline \multirow[t]{2}{*}{ EXstruct } & EXvoc & $1.27778^{*}$ & .41238 & .009 & 1.2569 & 2.2986 \\
\hline & control & $1.72222^{*}$ & .41238 & .000 & 1.7014 & 2.7431 \\
\hline \multirow[t]{2}{*}{ control } & EXvoc & $1-.44444^{*}$ & .41238 & .029 & -1.4653 & .5764 \\
\hline & EXstruct & $-1.72222^{*}$ & .41238 & .000 & -2.7431 & -.7014 \\
\hline
\end{tabular}

*. The mean difference is significant at the 0.05 level.

Therefore, Bonferroni test was applied and the results displays that there were significant differences among all three groups at the level of 0.05

The means of group 1, group 2 and group 3 are displayed in the figure 1 below. 
Figure 1: The means of group 1, group 2 and group 3

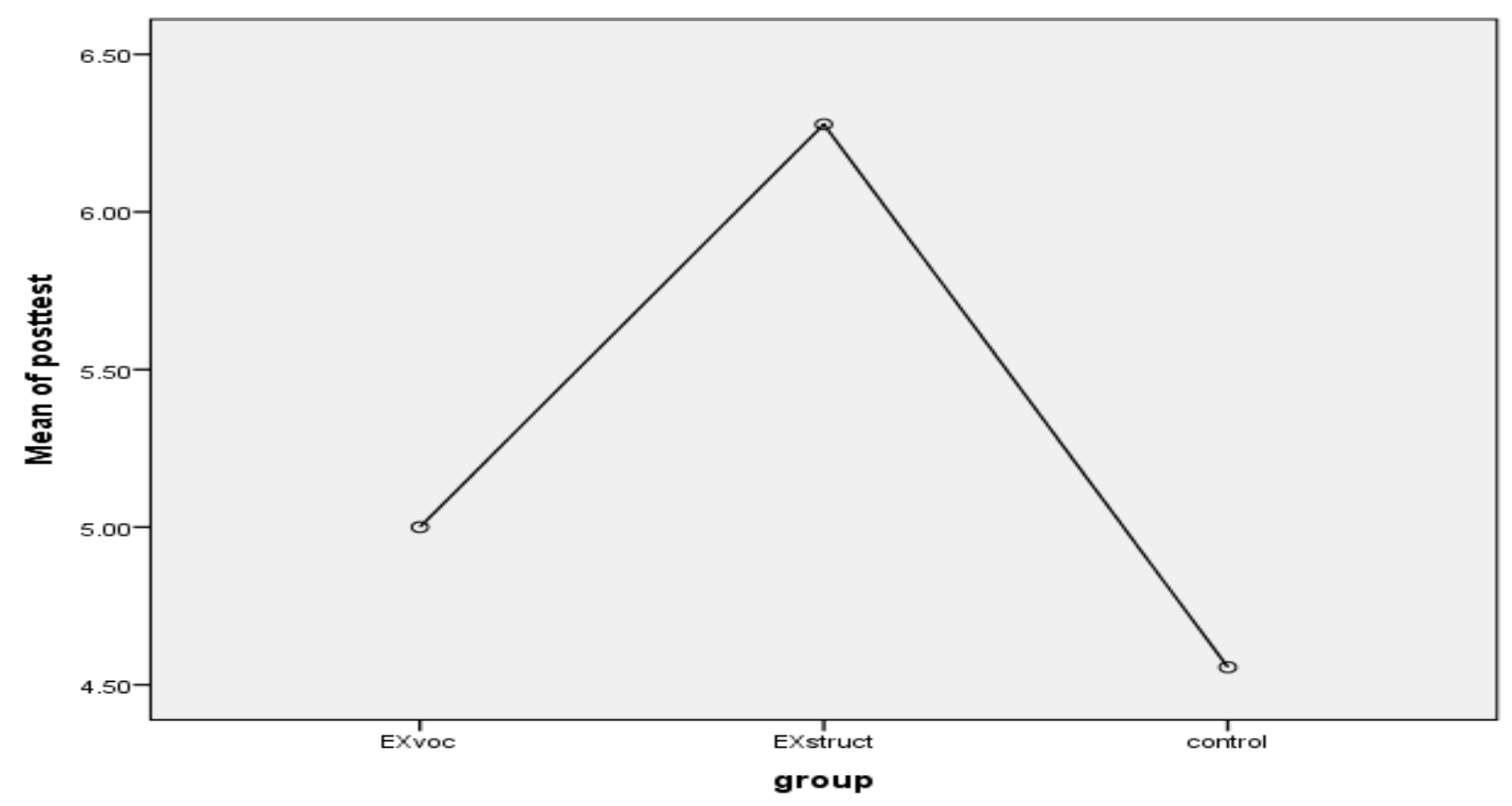

As the figure 1 demonstrates, the mean of experimental group with structure instruction is higher than the other two. This result can also be found out from the table 4 and 7. We can conclude that structure instruction is significantly the most beneficial one and the mere translation of newspaper content is the least beneficial in developing learner's newspaper reading comprehension.

The results of the interviews after treatment implementation revealed that the learners need both vocabularies and structure instruction for development of newspaper reading comprehension but they believe that teaching related specific structures are more advantageous than merely teaching related vocabularies. They mentioned that by getting familiar with different structures of newspaper content, their comprehension promotes and then they can learn the related vocabularies to improve their own comprehension more helpfully. 
Discussion and Conclusion

Regarding the significance of authentic materials instruction in educational setting (Shrum and Glisan, 2000; Richards, 2001; Kilickaya, 2004), newspaper can be regarded as a reliable source of information in different scientific, politic and social domains (Jarman and McClune, 2002; Korpan et al, 1997). Newspapers contain some scientific knowledge which is needed for critical thinking and can affect the person's attitudes, beliefs and behaviors. (Norris et al, 2003). Thus, we can conclude that understanding and assessing the newspapers' articles and reports is considered as an obvious characteristic of a scientifically literate individual (Korpan et al, 1997; Wellington, 1991).

The main purpose of the newspaper content is communication; consequently, the scientific information and knowledge in the newspapers include little particular knowledge which interrupts communication. Therefore, reading comprehension of scientific texts, which are not directly provided for teaching purpose, becomes difficult for the learners. In newspapers, some scientific facts can be seen but the related evidences for them may not be seen or even may not be identifiable (Martins, Mortimer, Osborne, Tsatarelis and JimenezAleixandre, 2001; Márquez and Prat, 2005).To have an appropriate interpretation of newspaper's scientific content, the learners should activate their previous scientific background knowledge which has been acquired at school that in some situations it is difficult for learners to make this activation and connection (Millar, 2006).

This study tries to investigate the effect of specific vocabularies and structures instruction on the upper intermediate EFL learners' newspaper reading comprehension development. The result of the study revealed that the three types of instruction in three groups were significantly effective in female upper intermediate EFL learners' newspaper reading comprehension development. Among which the instruction of related structures of newspaper content is more beneficial than the other two ones and the mere translation of 
newspaper content which was applied in the control group is the least beneficial in developing learner's newspaper reading comprehension.Based on the interviews' results after treatment fulfilment, the learners require bothinstruction of related vocabularies and structure for newspaper reading comprehensiondevelopment but they believe that teaching related specific structures are more advantageous than merely teaching related vocabularies. They pointed out that getting familiar with different structures of newspaper content is more important than just learning the related vocabularies for enhancing the newspaper reading comprehension.

We should be aware of generalizing the results of this study because of convenience sampling was utilized for the study. To control the effect of differences between male and female learners, the researcher selected the female learners. Small sample size, personal variable, age, limited educational context, and family background are the other kinds of limitation with which the researcher may face. Each of these variables can propose new questions for further researches in the same field in the future. 


\section{References}

Allan, D., (1995). Oxford Placement Test. Oxford: Oxford University Press. Guariento, W., \& Morley, J. (2001). Text and task authenticity in the EFL classroom. ELT Journal, $55(4), 347-353$.

Anderson, N. J. (1999). Exploring second language reading: issues and strategies. Canada:

Heinle \& Heinle. Breen, M.P. (1985). Authenticity in the language classroom. Applied Linguistics, 6, 60-70. Burns,

A. \& Seidlhofer, B. (2002). Speaking and pronunciation. In Schmitt, N. (Ed). An introduction to applied linguistics. New York : ARNOLD.

Jarman, R., \&McClune, B. (2002). A survey of the use of newspapers in science instruction by secondary teachers in Northern Ireland. International Journal of Science Education, 24(10), 997-1020.

Kilickaya. F. (2004). Authentic materials and cultural content in EFL classrooms .The Internet TESL Journal, 10 (7), 1-6.

Korpan, C. A., Bisanz, G. L., Bisanz, J. and Henderson, J. M. (1997). Assessing literacy in science: Evaluation of scientific news briefs. Science Education, 81, 515-532.

Márquez, C., Prat, A. (2005). Leer enclase de ciencias. Enseñanza de las Ciencias, 23(3), 431-440.

Martins, I., Mortimer, E., Osborne,J., Tsatarelis, Ch \& Jimenez-Aleixandre, P. (2001). Rethorics and Science Education. In A. Behrendt et al. (Eds.) Research in Science Education, Past, Present and Future (pp. 189-198).

Netherlands: Kluwer Acadèmic. Millar, R. (2006). Twenty First Century Science: Insights from the design and implementation of a scientific literacy approach in school science. International Journal of Science Education, 28(13), 1499-1521. 
Morrow, K. (1977). Authentic texts in ESP. In Holden, S.(Ed). English for specific purposes. London: Modern language publications.

Norris, S. P., \& Phillips, L. M. (2003). How literacy in its fundamental sense is central to scientific literacy. Science Education, 87, 224-240.

Nunan, D. (1989). Designing tasks for the communicative classroom. Cambridge: Cambridge University Press.

Lin, Y. (2004). The effect of authentic materials on motivation and reading achievement of EFL learners in Taiwan. Digital Dissertation Consortium. The University of Hong Kong Libraries.

Oliveras, O., Marquez, C., Sanmarti, N. (2013). The use of newspaper articles as a tool to develop critical thinking in science classes. International Journal of Science Education, 35(6), 1-37

Rogers, C., \& Medley, F., Jr. (1988). Language with a purpose: using authentic materials in the foreign language classroom. Foreign Language Annals, 21, 467-478.

Richards, J. C. (2001). Postscript: the ideology of TESOL. In Carter, R. \&Nunan, D. (Eds). The Cambridge guide to teaching English to speakers of other languages. Cambridge: Cambridge University Press.

Shrum, J. L. \& Glisan, E. W. (2000). Teacher's handbook: contextualized language instruction.

Boston: Heinle \& Heinle. Taylor, D. (1994). Inauthentic Authenticity or Authentic Inauthenticity? The Electronic Journal for English as a Second Language, 1(2).

Wellington, J. (1991). Newspaper science, school science: friends or enemies? International Journal of Science Education, 13(4), 363-372.

Widdowson, H.G.(1998). Context, community and authentic language. TESOL Quarterly, $32(4) .705-616$. 
Zohoorian, Z., Baghban, V. (2011).A review on the effectiveness of using authentic materials in ESP courses. English for Specific Purposes World, 31(10), 1-14. 